УДК 541.64:536.4

DOI 10.18101/2306-2363-2019-1-9-16

\title{
ТЕРМОСТОЙКОСТЬ ПОЛИФЕНИЛЕНХИНАЗОЛИНОВ
}

\section{(ㄷ Д. М. Могнонов}

доктор химических наук, профессор,

Байкальский институт природопользования СО РАН

670047, Улан-Удэ, ул. Сахьяновой, 6

Бурятский государственный университет, 670000, Улан-Удэ, ул. Смолина, 24a

\section{(c) О. Ж. Аюрова}

кандидат технических наук, научный сотрудник, Байкальский институт природопользования СО РАН 670047, Улан-Удэ, ул. Сахьяновой, 6 Бурятский государственный университет 670000, Улан-Удэ, ул. Смолина, 24a

E-mail: chem88@mail.ru

\section{(C) В. В. Хахинов}

доктор химических наук, профессор, Бурятский государственный университет, Улан-Удэ 670000, Улан-Удэ, ул. Смолина, 24а

E-mail:khakhinov@mail.ru

Изучена термическая деструкция хиназолинсодержащих полимеров и 2,4дифенилбензхиназолина, моделирующего элементарное звено полимера. Установлено, что термическая стабильность исследованных полифениленхиназолинов зависит от степени сопряженности фениленоксидных фрагментов и гетероцикла, поскольку преимущественное замещение фенильным радикалом в положение 2 гетероцикла копланарно, тогда как замещение фенильным радикалом в положение 4 гетероцикла - ортогонально.

Ключевые слова: бензохиназолин; полифениленхиназолины; термостойкость; пиролитическая хроматография; газовая хроматография; сопряжение; деструкция.

\section{Для цитирования:}

Могнонов Д. М., Аюрова О. Ж., Хахинов В. В. Термостойкость полифениленхиназолинов // Вестник Бурятского государственного университета. Химия. Физика. 2019. Вып. 1. С. 9-16.

На практике критерием пригодности полимера для использования его при данной температуре является теплостойкость, однако предельная ее величина определяется термостойкостью. При возрастании теплостойкости полимеров наступает момент, когда начинается химическое или термическое и окислительное разложение полимера. Поэтому отбор полимеров обычно производится с учетом, в первую очередь, их термостойкости.

Полученный обширный экспериментальный материал, касающийся термических характеристик различных классов полимеров, позволил [1-3] выявить ряд факторов, определяющих теплостойкость и термостойкость полимеров: 
- устойчивость химической структуры;

- жесткость полимерной цепи;

- межмолекулярное взаимодействие;

- симметричность звеньев макромолекулы;

- кристалличность (физическая структура);

- наличие трехмерных структур.

Наиболее важным фактором, определяющим предельную термостойкость полимеров, является устойчивость фрагментов, составляющих полимерную молекулу, к термическому и окислительному воздействию. С этих позиций полигетероарилены, представляющие собой систему чередующихся карбо- и гетероциклов определило их основное практическое предназначение. Среди большой группы полигетероариленов, таких как полибензимидазолы [4], полиоксадиазолы [5], полибензоксазолы [6], полибензтиазолы [7], полихинансолины [8] и др., несомненный интерес представляют полимеры, содержащие хиназолиновый цикл [9].

Однако, основная часть информации, касающаяся их термостабильности, получена с помощью экспресс-методов. В настоящей работе предпринята попытка более подробного изучения термической деструкции хиназолинсодержащих полимеров.

\section{Экспериментальная часть}

Полифениленхиназолины были получены по известным методикам [10].

Термический анализ полимеров. Предварительно тонкоизмельченный образец полимера (дисперсность $200 \mathrm{MEШ)} \mathrm{сушили} \mathrm{при} 200-250^{\circ} \mathrm{C}$ в течение 2-3 ч и остаточном давлении $10^{-2}$ мм. рт. ст.

Пиролиз полимеров и модельного соединения выполняли в замкнутой пиролитической ячейке в диапазоне температур $300-700^{\circ} \mathrm{C}$ в вакууме $10^{-2}-10^{-4}$ мм. рт. ст. Время выдержки при каждой температуре 1 ч. Продукты пиролиза исследовали методом газовой хроматографии [11].

ИК-спектры снимали на спектрометре ALPHA (Bruker) в диапазоне волновых чисел 4000-400 см-1. Образцы получали прессованием с $\mathrm{KBr}$.

Динамический термогравиметрический анализ выполняли на синхронном термическом анализаторе STA 449C (Netzsch) при скорости нагревания 5\% на воздухе и в атмосфере инертного газа (аргон).

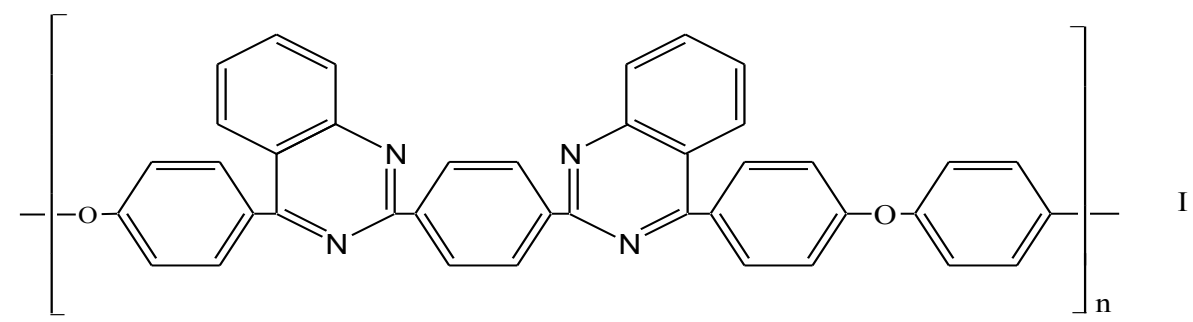


<smiles>Cc1ccc(-c2nc(-c3ccc(Oc4ccc(-c5nc(-c6ccc(O)cc6)nc6ccccc56)cc4)cc3)nc3ccccc23)cc1</smiles><smiles></smiles><smiles>CC(=O)OCCCc1nc(-c2ccccc2)nc2ccccc12</smiles>

Рис. 1. Исследуемые полимеры

\section{Результаты и обсуждение}

Объектами исследования послужили четыре полимера (I-IV), различающиеся порядком присоединения фениленоксидных фрагментов к хиназолиновому циклу, а также 2,4-дифенилбензхинолин, моделирующий элементарное звено полимера (схема).

Исследуемые полимеры I-IV, в выбранных нами условиях практически не теряют массу при нагревании в вакууме до температур $380-450^{\circ} \mathrm{C}$ (рис. 2). Выше $450^{\circ} \mathrm{C}$ наблюдается выделение заметных количеств твердых и жидких низкомолекулярных веществ, основную массу которых составляют вещества олигомерного типа. Одновременно выделяются газообразные продукты разложения, хро- 
матографический анализ которых показал наличие $\mathrm{CO}, \mathrm{CH}_{4}$ и $\mathrm{H}_{2}$. При более высоких температурах наступает глубокое разложение, сопровождающееся выделением твердых, жидких и газообразных продуктов деструкции, а также образование неплавкого и нерастворимого коксообразного остатка.

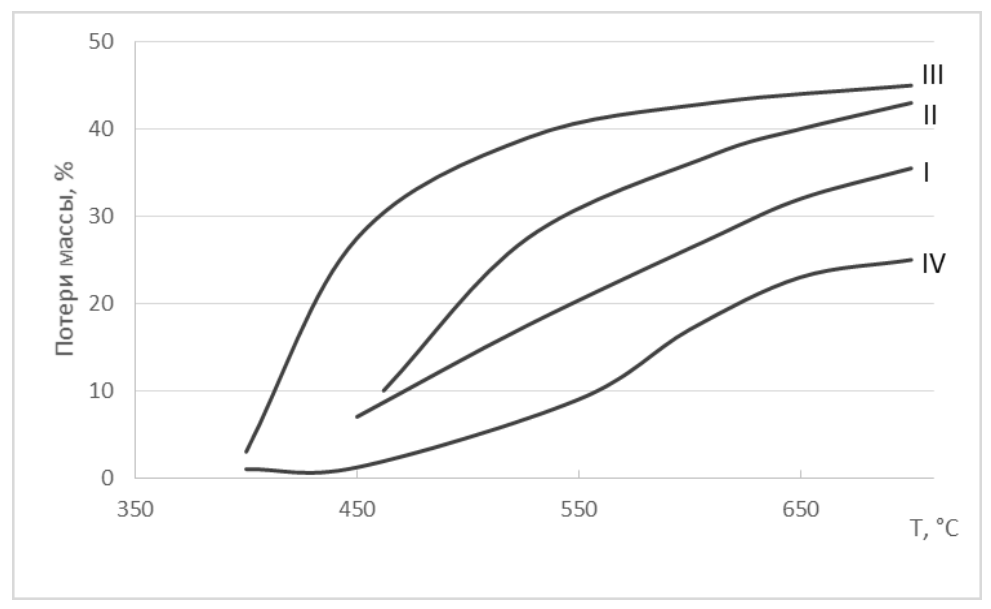

Рис. 2. Потеря массы полимерами I-IV при деструкции в вакууме в течение 1 ч нагревания при каждой температуре

Как видно из данных по газовыделению (рис. 3-5) полимера I-IV в интервале температур $400-700^{\circ} \mathrm{C}$ можно расположить по мере убывания термостойкости следующим образом:

$$
\mathrm{IV} \rightarrow \mathrm{II} \rightarrow \mathrm{III} \rightarrow \mathrm{I}
$$

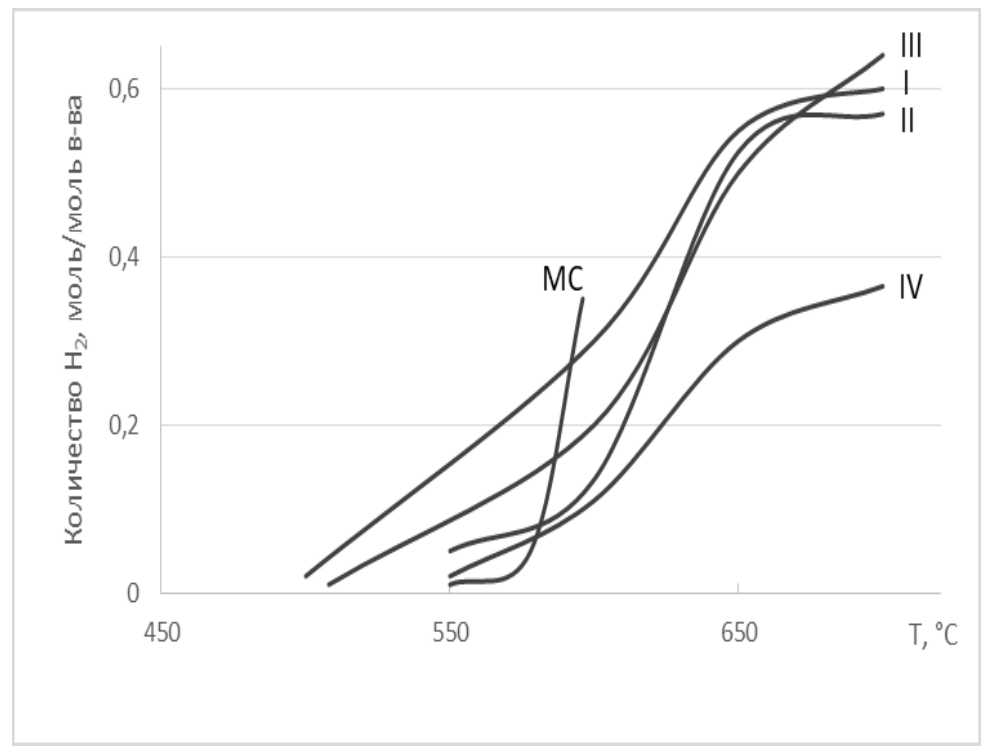

Рис. 3. Количество $\mathrm{H}_{2}$, образующегося при температуре $500-700^{\circ} \mathrm{C}$ при деструкции полимеров IIV и модели MC в вакууме 


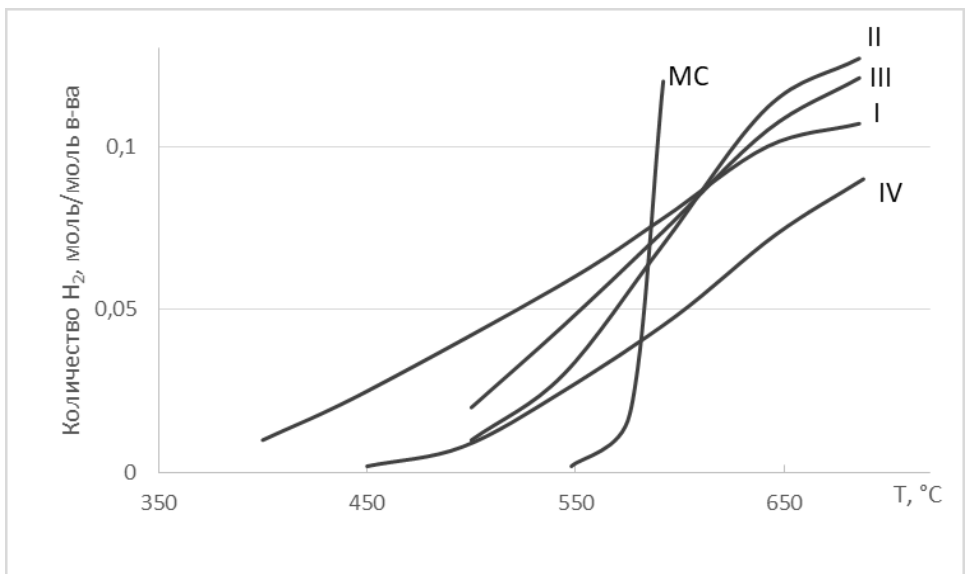

Рис. 4. Количество метана, образующегося при термической деструкции полимеров I-IV и модели МС в течение 1 ч нагревания при каждой температуре

Появление в газообразных продуктах деструкции полимера IV, не содержащего кислорода, до 0,2 моль/основ. моль окиси углерода может быть объяснено наличием концевых анилидных групп. Полученное значение выделившегося СО соответствует полимеру с $\mathrm{n}=50$, что отвечает молекулярной массе $20000 \mathrm{kDa}$ и сопоставимо с величиной его характеристической вязкости $[\eta]=0,7$ дл/г $\left(\mathrm{H}_{2} \mathrm{SO}_{4}\right.$, $\left.25^{\circ} \mathrm{C}\right)$.

Данные, полученные при термической деструкции модельного соединения (MC), свидетельствуют, что заметное количество газообразных продуктов появляется при температурах выше $500^{\circ} \mathrm{C}$ (рис. 3-5). Это свидетельствует о том, что при температурах ниже $500^{\circ} \mathrm{C}$, хиназолиновый цикл вполне устойчив. Так, по данным ИК-спектроскопии, интенсивность поглощения, характеризующего хиназолиновый цикл, вплоть до $500^{\circ} \mathrm{C}$ не меняется. Можно полагать, что термическая устойчивость полифениленхиназолинов практически не лимитируется устойчивостью гетероцикла.

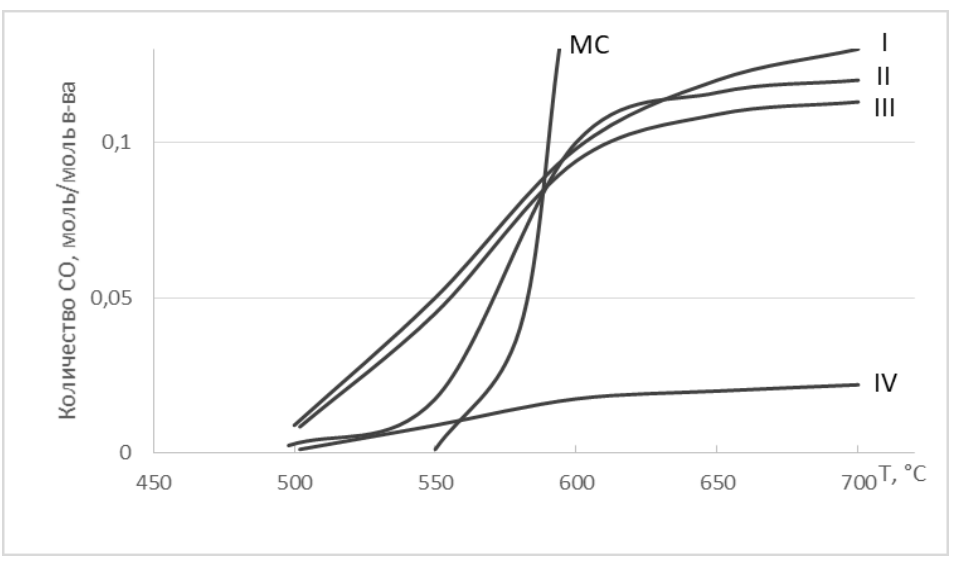

Рис. 5. Количество CO, образующегося при термической деструкции полимеров I-IV и модели МС в течение 1 ч нагревания при каждой температуре 
Из литературы известно, что положения 2 и 4 хиназолина неравноценны [12]. Так, 2-фениленовый фрагмент копланарен гетероциклу, тогда как 4фениленовый гетероциклу ортогонален [13]. Таким образом, в положении 2 связь более стабильна, чем в положении 4 , следовательно, термическая стабильность полимеров I-IV, в значительной мере зависит от степени сопряженности фениленоксидных фрагментов и гетероцикла. По всей вероятности, полимер с чередующимися 2,4-2', 4 -присоединением будет более термостабилен, чем полимер с 2,2'-4,4'-присоединением. Действительно, данные температурной деструкции полимеров I-IV, полученные при температурах ниже температур активного газовыделения (рис. 6), подтверждают заключение, сделанное при анализе результатов высокотемпературной деструкции.

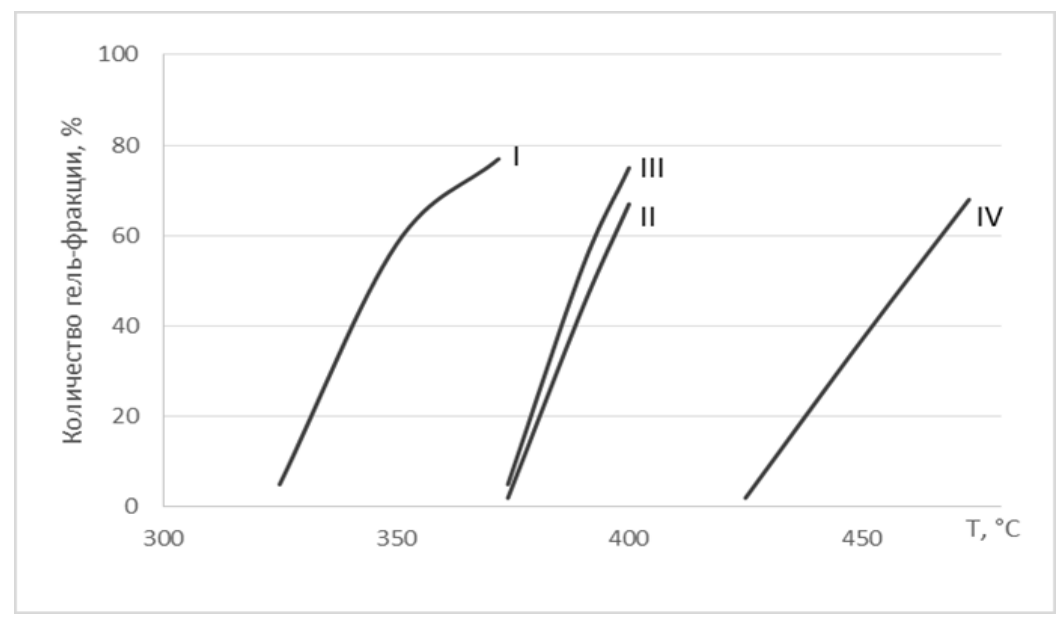

Рис. 6. Количество геля, образующегося при термической деструкции полимеров I-IV в течение 1 ч нагревания при каждой температуре

Сделанные выводы подтверждаются данными динамического термогравиметрического анализа, который показал, что потери массы исследуемых полимеров при $600^{\circ} \mathrm{C}$ составляют $3-15 \%$, хотя, в условиях термической деструкции при $600^{\circ} \mathrm{C}$ и остаточном давлении $10^{-3}$ мм. рт. ст., потери массы указанных полимеров достигают $25-45 \%$.

ИК-спектроскопия твердых и жидких продуктов деструкции полимеров I-IV свидетельствует о наличии молекул олигомерного характера - спектры твердых и жидких продуктов идентичны спектрам исходных полимеров.

Таким образом, можно заключить, что на термическую устойчивость полимеров I-IV значительное влияние оказывает степень сопряженности фениленоксидных фрагментов и гетероцикла.

Работа выполнена в рамках государственного задания Байкальского института природопользования СО РАН.

Литература

1. Коршак В. В. Термостойкие полимеры. - М.: Наука, 1969. - 411 с. 
2. Фрейзер А. Г. Высокотермостойкие полимеры / Под ред. А.Н. Праведникова. - М.: Химия, 1971. - 294 с.

3. Виноградова С. В., Васнев В. А. Поликонденсационные процессы и полимеры. М.: Наука, 2000. - 372 с.

4. Vogel H. A, Marvel C. S. Polybenzimidazoles, new thermally stable polymers // J. Polym. Sci. — 1961. - V. 50. - P. 511-539.

5. Виноградова С. В., Выгодский Я. С. Кардовые полимеры // Успехи химии. - 1973. — Т. 42, № 7. - С. 1225-1264.

6. Русанов А. Л., Хотина И. А. Поликонденсация с карбонилированием (карбонилизационная поликонденсация) - новый метод синтеза гетероцепных полимеров // Высокомолек. соединения. Сер. Б. - 1994. - Т. 36, № 8. - С. 1399-1408.

7. Коршак В. В., Максимов А. Д. Серусодержащие цианоцепные полимеры // Итоги науки. Химия и технология высокомолекулярных соединений. - 1971. - Т. 3. - С. 60-84.

8. Stille J. K. Polyquinolines (reviews) // Macromolecules. - 1981. - V. 14, № 3. P. 870-880.

9. Одноралова В. Н., Васильева-Соколова Е. А. Полимеры на основе диаминодикарбоновых кислот и области их применения // Итоги науки и техники. Сер. Химия и технология высокомолекулярных соединений. - М.: ВИНИТИ. - 1978. - Т. 12. - С. 47-126.

10. Пономарев И. И., Никольский О. Г., Волкова Ю. В., Захаров А. В. Новые жесткоцепные сополинафтоиленбензимидазолы и пленки на их основе // Высокомол. соед. Серия А. - 1994. - Т. 36, № 9. - С. 1429-1436.

11. Mognonov D. M., Varga J., Batotsyrenova A. I., Samsonova V. G., Izyneev A. A. Etude de decomposition thermique des polyheteroarylenes // J. of Thermal Analysis. - 1985. - V. 30. - P. 1053-1062.

12. Гетероциклические соединения. В 6 томах. - М.: Изд-во ИЛ. - 1960. - Т. 6. $288 \mathrm{c}$.

13. Линдеман С. В., Пономарев И. И., Стручков Ю. Т., Виноградова С. В. Синтез и кристаллическая структура 6-амино-2-(р-аминофенил)-4-фенилхиназолина // Изв. АН СССР. Сер. Химическая. - 1990. - Т. 2. - С. 412-419.

\section{THERMAL RESISTANCE OF POLYPHENYLENEQUINAZOLINES}

\section{M. Mognonov}

Doctor of Chemical Sciences, Professor,

Baikal Institute of Nature Management SB RAS

670047, Ulan-Ude, Sakhyanovoi Str., 6

Buryat State University, Ulan-Ude

670000, Ulan-Ude, Smolina Str., 24a

O. Zh. Ayurova

Candidate of Techical Sciences, Researcher,

Baikal Institute of Nature Management SB RAS

670047, Ulan-Ude, Sakhyanovoi Str., 6

Buryat State University, Ulan-Ude

670000, Ulan-Ude, Smolina Str., 24a

E-mail: chem88@mail.ru

V. V. Khakhinov

Doctor of Chemical Sciences, Professor,

Buryat State University, Ulan-Ude

670000, Ulan-Ude, Smolina Str., 24a 
Studied was the thermal degradation of quinazolin-containing polymers and 2,4diphenylbenzquinazolin modeling the elementary link of polymer. It was revealed that the thermal stability of investigated phenylbenzquinazolins depends on the extent of phenyleneoxid fragments and heterocycle, as a predominant substitution of a phenyl radical in position 2 of heterocycle - coplanar, whereas the substitution of a phenyl radical in position 4 of the heterocycle - orthogonal.

Keywords: benzoquinazoline; polyphenylenequinazoline; thermoresistance; pyrolytic chromatography; gas chromatography; conjugation; destruction. 